\section{Essential Oil Yields and Quality of Fennel Grown in Nova Scotia}

\author{
Kelly M. Bowes and Valtcho D. Zheljazkov ${ }^{1}$ \\ Department of Plant and Animal Sciences, Nova Scotia Agricultural College, \\ P.O. Box 550 Truro, NS, B2N 5E3, Canada
}

Additional index words. Foeniculum vulgare, Apiaceae, essential oil, steam distillation

\begin{abstract}
Field and laboratory experiments were conducted at two sites in Nova Scotia during 2001 and 2002 to assess the potential to grow fennel (Foeniculum vulgare Mill.) as an essential oil crop in the Maritime region of Canada. Three cultivars-'Shumen', 'Berfena', and 'Sweet Fennel' — and two seeding dates-24 May and 8 June-were evaluated. Essential oil yields and composition were determined and compared to commercially available fennel essential oil from the U.S. The highest herbage yields were produced by 'Shumen' from the earlier seeding date. Essential oil content and yields were lowest in 'Sweet Fennel' and highest in 'Shumen'. The major component of the essential oil was anethole, $47 \%$ to $80.2 \%$. Other major components of the essential oil were methyl chavicol, fenchone, $\alpha$-phellandrene, $\alpha$-pinene, ortho cymene, $\beta$-phellandrene, fenchyl acetate, $\beta$-pinene, and apiole. The essential oil composition was unique to each cultivar. The highest methyl chavicol content was in 'Shumen', while the highest concentration of phellandrene, fenchyl acetate and apiole were detected in 'Sweet Fennel' oil. Fenchone, ortho cymene, $\beta$-pinene, $\alpha$-phellandrene, and $\alpha$-pinene were the highest in 'Berfena'. The composition of the oil was similar to the commercially purchased oil and met industry requirements of oil composition. The results suggest there is potential to grow fennel as an essential oil crop in Nova Scotia.
\end{abstract}

Fennel is an essential oil producing aromatic plant that belongs to the Apiaceae family. Over $90 \%$ of fennel essential oil is stored in sectretory channels in the mature seeds and essential oil is also stored in sectretory channels throughout the plant (Peterson et al., 1993). Essential oil of fennel is used as a flavour and aromatic agent in breads, soups, and other food products. Aromatherapy and pharmaceutical industries utilize fennel essential oil. The most important bioactive components of fennel essential oil are fenchone and anethole (Charles et al., 1993; Reichardt and Pank, 1993). Research has shown that the growth of some bacteria can be inhibited by essential oil of fennel (Marotti et al., 1994).

The essential oil of fennel herbage has been reported to range between 0.69 and 4.6\% (Cavalerio et al., 1993; Dnyansagar and Jahagirdar, 1980; Garcia-Jimenez et al., 2000; Marotti et al., 1994). The main component of the oil is anethole, up to $80 \%$. For a good quality fennel essential oil there should not be high concentrations of methyl chavicol or fenchone.

Received for publication 17 Oct. 2003. Accepted for publication 15 June 2004. This paper is part of a thesis submitted by K. Bowes in partial fulfillment of a Masters of Science degree. This study has been supported by a NSERC grant awarded to Kelly Bowes and by Nova Scotia Technology Development Program project \# DEV20-079 of Valtcho Zheljazkov (Jeliazkov). Authors thank Minas Seed Inc. for providing a field site and logistics, James Pincock from Dalhousie University for providing access to and assistance with the GC/MS system, Raj Lada and Norman Goodyear for critical review of the manuscript and suggested improvements, and the Cropping Systems Research Program at NSAC for technical support.

${ }^{1}$ To whom reprint requests should be addressed; e-mailvjeliazkov@nsac.ns.ca.
Oil with no more than $10 \%$ methyl chavicol or $7.5 \%$ fenchone would be acceptable (Bilia et al., 2002). fennel and other essential oil crops are depended on many factors such as climate, cultivar, seeding date, harvest date, weed pressure, plant disease, and management practices (Clark and Menary, 1979; Fahlen et al., 1997; Frank et al., 1987; Gill and Randhawa, 1996; Kothari et al., 1989; Kothari and Singh 1994; Lenardis et al., 2000; Marotti et al., 1996; Zheljazkov and Zhalnov, 1995). Fennel is grown as an essential oil producing crop in many areas of the world including the United States, Europe, and Asia. While fennel is commonly grown in the Maritime region of Canada as a culinary crop, there has been no evaluation of the effect of the regional climate on the essential oil productivity and quality.

'Berfena' and 'Shumen' were developed in Germany and in Bulgaria respectively, as early maturing varieties for essential oil production (Reichardt and Pank, 1993; Zheljazkov et al., 1996). 'Sweet Fennel' is commonly grown in North America (Charles et al., 1993). The above three cultivars were chosen for this study based on having been developed for essential oil production and their productivity in similar climates to Nova Scotia.

Cultivars of fennel were evaluated as potenin Nova Scotia. Most horticultural crops in Atlantic Canada are grown in Nova Scotia in the area around Canning (plant hardiness zone 6 ) and some in the area around Truro (plant hardiness zone 5). Furthermore, growers in the region are looking for new cash crops. Therefore, to make this study more representative, these two locations were chosen to conduct the experiments.
The essential oil quality and productivity of tial new cash crops for essential oil production
The objective of this research was to determine the potential to grow fennel as an essential oil crop in the Maritime region. The effect of cultivar and seeding dates were also evaluated. To meet these objectives field experiments and laboratory analysis were carried out in 2001 and 2002.

\section{Materials and Methods}

Experimental design. Field experiments were carried out at two Nova Scotia (Canada) locations, Truro and Canning in 2001 and 2002. The experiments were $2 \times 3$ factorial designs. The fields for each experiment were blocked into four areas. The two factors were seeding date (24 May and 8 June) and cultivar ('Shumen', 'Berfena', and 'Sweet Fennel').

Plant material. 'Berfena' and 'Sweet Fennel' seeds were purchased from Richters Seeds in Canada and 'Shumen' seeds were acquired from the Research Institute for Roses, Aromatic and Medicinal Plants in Kazanluk, Bulgaria. Before seeding fields were amended with $\mathrm{N}$ at $170 \mathrm{~kg} \cdot \mathrm{ha}^{-1}$ and $\mathrm{K}$ at $65 \mathrm{~kg} \cdot \mathrm{ha}^{-1}$ and disked and harrowed, based on the soil tests no amendment of phosphorus was needed. Plots were $2 \times 3 \mathrm{~m}$ with four rows of fennel in each plot, $60 \mathrm{~cm}$ apart. Fennel was direct seeded into the field at rates of $15 \mathrm{~kg} \cdot \mathrm{ha}^{-1}$ on 24 May and 8 June. Plants were harvested during flowering, on the same day for each location, and dried in forced air dryers for $3 \mathrm{~d}$ at $25^{\circ} \mathrm{C}$ before oil extraction.

Essential oil extraction. Steam distillation was used to extract the essential oil using a modified Clevenger collector apparatus (Guenther, 1948) from Quickfit glassware, England. Sample size was $200 \mathrm{~g}$ of dried plant material. Distillation time was $120 \mathrm{~min}$. After extraction oil was stored in tinted glass vials in $-5{ }^{\circ} \mathrm{C}$ freezers until compositional analysis.

Essential oil analysis. For the analysis 50 $\mu \mathrm{L}$ of oil was diluted in $0.5 \mathrm{~mL}$ HPLC-grade hexane for injection into the gas chromatography instrument (GC) (PerkinElmerTurboMass mass spectrometer). The GC column was a Supelco MDN-55 fused silica capillary column, $30 \mathrm{~m} \times$ $0.25 \mathrm{~mm}$ ID and a film thickness of $0.5 \mu \mathrm{m}$.

The following GC temperature program was used to separate the components of the essential oil: the initial temperature of $75^{\circ} \mathrm{C}$, for $4 \mathrm{~min}$., followed by $4{ }^{\circ} \mathrm{C} \cdot \mathrm{min}^{-1}$ increase to $199^{\circ} \mathrm{C}$ with a total run time of $35 \mathrm{~min}$. The injection volume was $1.0 \mu \mathrm{L}$ and the injection temperature was $240{ }^{\circ} \mathrm{C}$. Helium, the carrier gas, flowed at 1.0 $\mathrm{mL} \cdot \mathrm{min}^{-1}$. Both flame ionization detection (FID) and mass spectrum (MS) analyses were performed. Component concentration was determined based on the peak area from FID detection. Commercial grade standards (Aldrich, Canada) were used to identify the components in the essential oil. In addition, steam distilled commercial fennel seed essential oil grown in the United States was purchased from ATL Canada for compositional comparison.

Statistical analysis. Statistical analysis software, SAS version 8.0 (SAS Institute, 2000) was used to evaluate the significance of the difference between the two-way interaction of cultivar by seeding date, and the two main effects of cultivar and seeding date. Each year 
and location was analyzed separately due to the differences between locations and years. Tukey's studentized range test was used to compare the mean values of the treatments when significant differences were shown through the analysis of variance. Mean values were considered significantly different when $P<$ 0.05 . Transformations were performed as was necessary to meet ANOVA model assumption of normal distribution of residuals. Means presented are original raw data.

\section{Results}

Herbage yields ranged from 275 to 16,016 $\mathrm{kg} \cdot \mathrm{ha}^{-1}$ (fresh) and from 60 to $3,600 \mathrm{~kg} \cdot \mathrm{ha}^{-1}$ (dry) (Table 1). 'Shumen' was the fennel cultivar with the highest yields on a fresh and dry weight basis compared to 'Berfena' and 'Sweet Fennel'. Overall the highest yields were from the first seeding date.

Essential oil content from dried herbage ranged from $0.31 \%$ to $2.17 \%$ and essential oil yields ranged from 0.05 to $1.96 \mathrm{~L} \cdot \mathrm{ha}^{-1}$ (Table 2 ). The highest essential oil content and yield was in fennel planted on the first seeding date. Overall 'Sweet Fennel' had the lowest essential oil content and yields compared to 'Shumen' and 'Berfena'. However, in 2002 'Sweet Fennel' from the second seeding date in Truro had more than double the essential oil content and yields then the other treatment combinations.

Anethole was the main component in the fennel essential oil with concentrations ranging from $47 \%$ to $80.2 \%$ (Tables 3-6). Generally, anethole concentration decreased with a delay in seeding date. In fennel grown in Truro in 2001 'Berfena' had lower anethole concentration then 'Sweet Fennel' and Shumen' (Table 4).

Fenchone, ortho cymene, $\alpha$-phellandrene, $\alpha$-pinene and $\beta$-pinene were greatest in 'Berfena' essential oil and lowest in 'Sweet Fennel' essential oil (Tables 3-6). 'Shumen' essential oil had the greatest concentration of methyl chavicol. Apiole and $\beta$-phellandrene were greatest in 'Sweet Fennel' oil. 'Berfena' essential oil contained low g-terpine levels compared to 'Shumen' and 'Sweet Fennel' essential oil. Fenchyl acetate was highest in 'Sweet Fennel' oil and lowest in 'Berfena' oil. $\beta$-Pinene and $\alpha$-pinene were greatest in the first seeding date, conversely, the concentration of $\alpha$-phellandrene was greatest in the second seeding date.

Anethole was the main component of essential oil extracted from 'Sweet Fennel' grown in the U.S. consisting of $77 \%$ of the oil (Table 7). Fenchone (9.83\%), methyl chavicol $(4.46 \%)$, limonene $(3.34 \%)$, and $\alpha$-pinene $(2.27 \%)$ were the remaining main components. Those components comprised of $96.96 \%$ of the essential oil with the remaining $3 \%$ of the oil being made up of numerous components in trace amounts $(<1 \%)$.

\section{Discussion}

Herbage yields ranged from 275 to 16,016 $\mathrm{kg} \cdot \mathrm{ha}^{-1}$ (fresh) and from 60 to $3,600 \mathrm{~kg} \cdot \mathrm{ha}^{-1}$ (dry) depending on year, location, seeding date and cutlivar. These yields are slightly lower than have been reported by other authors. Butain and Chung (1994) reported herbage dry weights between 4.16 and $7.79 \mathrm{t} \cdot \mathrm{ha}^{-1}$. In this study, the highest yields were produced by 'Shumen' $\left(3,991\right.$ to $16,016 \mathrm{~kg} \cdot \mathrm{ha}^{-1}$ (fresh) and 964 to $3,600 \mathrm{~kg} \cdot \mathrm{ha}^{-1}$ (dry) and the first seeding date. 'Berfena' and 'Sweet Fennel' performed better in the earlier seeding date.

The three cultivars of fennel did not reach seed formation in either Truro or Canning during both 2001 and 2002. Similar problems have been reported when growing fennel in Alberta, Canada (Embong et al., 1977). For seed formation in Nova Scotia fennel would need to be seeded earlier than the earliest date that was tested, 24 May. Furthermore, the results show that an earlier seeding date produced greater herbage yields. 'Shumen' and 'Berfena' performed well with slightly lower dry yields than have been reported.

Essential oil content from dried herbage in our experiments ranged from $0.31 \%$ to $2.17 \%$. With the exception of Truro in 2002 'Sweet Fennel' had low essential oil content. The exceptionally high essential oil content from 'Sweet Fennel' from Truro (2002) was not high enough to compensate for the very low herbage yields that were produced in that location and year. There was greater essential oil content extracted from 'Berfena' and 'Shumen' than from 'Sweet Fennel'. The oil content from 'Shumen' and 'Berfena' is similar to the wide range of composition that was found in tested commercial fennel and reported in previous research studies. Although the dynamic of essential oil content during the vegetative period was not measured, essential oil content in fennel increases as the plant matures (Gupta

Table 1. Herbage yields of fennel depending on location, seeding date, and cultivar.

\begin{tabular}{|c|c|c|c|c|c|c|c|c|c|}
\hline \multirow[b]{3}{*}{$\begin{array}{l}\text { Seeding } \\
\text { date }\end{array}$} & \multirow[b]{3}{*}{ Cultivar } & \multicolumn{4}{|c|}{2001} & \multicolumn{4}{|c|}{2002} \\
\hline & & \multicolumn{2}{|c|}{ Canning } & \multicolumn{2}{|c|}{ Truro } & \multicolumn{2}{|c|}{ Canning } & \multicolumn{2}{|c|}{ Truro } \\
\hline & & $\begin{array}{c}\text { Fresh } \\
\text { yield } \\
\left(\mathrm{kg} \cdot \mathrm{ha}^{-1}\right)\end{array}$ & $\begin{array}{c}\text { Dry } \\
\text { yield } \\
\left(\mathrm{kg} \cdot \mathrm{ha}^{-1}\right)\end{array}$ & $\begin{array}{c}\text { Fresh } \\
\text { yield } \\
\left(\mathrm{kg} \cdot \mathrm{ha}^{-1}\right)\end{array}$ & $\begin{array}{c}\text { Dry } \\
\text { yield } \\
\left(\mathrm{kg} \cdot \mathrm{ha}^{-1}\right)\end{array}$ & $\begin{array}{c}\text { Fresh } \\
\text { yield } \\
\left(\mathrm{kg} \cdot \mathrm{ha}^{-1}\right)\end{array}$ & $\begin{array}{c}\text { Dry } \\
\text { yield } \\
\left(\mathrm{kg}^{2} \cdot \mathrm{ha}^{-1}\right)\end{array}$ & $\begin{array}{c}\text { Fresh } \\
\text { yield } \\
\left(\mathrm{kg} \cdot \mathrm{ha}^{-1}\right)\end{array}$ & $\begin{array}{c}\text { Dry } \\
\text { yield } \\
\left(\mathrm{kg} \cdot \mathrm{ha}^{-1}\right)\end{array}$ \\
\hline \multirow[t]{3}{*}{24 May } & Berfena & $11783 a^{z}$ & $2975 \mathrm{ab}$ & $2679 \mathrm{~b}$ & $588 \mathrm{~b}$ & 3979 bc & $1211 \mathrm{~b}$ & $996 \mathrm{~b}$ & $371 \mathrm{~b}$ \\
\hline & Shumen & $10775 \mathrm{ab}$ & $3600 \mathrm{a}$ & $7667 \mathrm{a}$ & 1933 a & $16016 \mathrm{a}$ & $3324 \mathrm{a}$ & 3991 a & $964 \mathrm{a}$ \\
\hline & Sweet Fennel & $5325 \mathrm{ab}$ & $1450 \mathrm{~b}$ & $1246 b$ & $396 \mathrm{bc}$ & $2746 \mathrm{~cd}$ & $848 \mathrm{~b}$ & $324 \mathrm{~b}$ & $201 \mathrm{~b}$ \\
\hline 8 June & Berfena & $817 \mathrm{c}$ & $183 a b$ & $612 \mathrm{~b}$ & $91 \mathrm{~d}$ & $612 \mathrm{~d}$ & $91 \mathrm{c}$ & $704 \mathrm{~b}$ & $266 \mathrm{~b}$ \\
\hline \multicolumn{10}{|l|}{$P$ value } \\
\hline Date & & $<0.0001$ & $<0.0001$ & NS & $<0.0001$ & $<0.0001$ & $<0.0001$ & NS & NS \\
\hline Cultivar & & $<0.0001$ & 0.0221 & 0.0071 & $<0.0001$ & $<0.0001$ & $<0.0001$ & $<0.0001$ & $<0.0001$ \\
\hline Date $\times$ cultivar & & $<0.0001$ & NS & NS & $<0.0001$ & $<0.0001$ & $<0.0001$ & NS & NS \\
\hline
\end{tabular}

${ }^{{ }^{2}}$ Means within columns followed by different letters are significantly different at $P<0.05$.

Table 2. Essential oil yields of fennel as affected by seeding date, and cultivar.

\begin{tabular}{|c|c|c|c|c|c|c|c|c|c|}
\hline \multirow{2}{*}{$\begin{array}{l}\text { Seeding } \\
\text { date }\end{array}$} & \multirow{2}{*}{ Cultivar } & \multicolumn{4}{|c|}{2001} & \multicolumn{4}{|c|}{2002} \\
\hline & & \multicolumn{2}{|c|}{ Canning } & \multicolumn{2}{|c|}{ Truro } & \multicolumn{2}{|c|}{ Canning } & \multicolumn{2}{|c|}{ Truro } \\
\hline \multirow{2}{*}{24 May } & Shumen & $0.53 \mathrm{~b}$ & $1.80 \mathrm{a}$ & $0.50 \mathrm{abc}$ & $0.96 \mathrm{a}$ & $0.67 \mathrm{a}$ & $2.20 \mathrm{a}$ & $0.72 \mathrm{~b}$ & $0.71 \mathrm{a}$ \\
\hline & Sweet Fennel & $0.47 \mathrm{~b}$ & $0.65 \mathrm{~b}$ & $0.31 \mathrm{c}$ & $0.13 \mathrm{~cd}$ & $0.42 \mathrm{~b}$ & $0.36 \mathrm{~cd}$ & $0.88 \mathrm{~b}$ & $0.18 \mathrm{~b}$ \\
\hline \multirow[t]{2}{*}{8 June } & Berfena & $1.05 \mathrm{a}$ & $0.16 \mathrm{~b}$ & $0.56 \mathrm{abc}$ & $0.18 \mathrm{~cd}$ & $0.63 \mathrm{a}$ & $0.51 \mathrm{~d}$ & $0.47 \mathrm{~b}$ & $0.13 \mathrm{~b}$ \\
\hline & Shumen & $0.82 \mathrm{a}$ & $0.47 \mathrm{~b}$ & $0.63 \mathrm{ab}$ & $0.31 b c$ & $0.67 \mathrm{a}$ & $0.81 \mathrm{~b}$ & $0.71 \mathrm{~b}$ & $0.74 \mathrm{a}$ \\
\hline Date & & 0.0033 & $<0.0001$ & NS & $<0.0001$ & NS & $<0.0001$ & NS & NS \\
\hline Cultivar & & 0.019 & 0.0009 & 0.0006 & $<0.0001$ & 0.0153 & $<0.0001$ & 0.0174 & 0.0018 \\
\hline Date $\times$ cultivar & & NS & 0.0120 & 0.0434 & $<0.0001$ & NS & 0.0003 & 0.0107 & NS \\
\hline
\end{tabular}

${ }^{\mathrm{z}}$ Means within columns followed by different letters are significantly different at $P<0.05$. 
et al., 1995). Essential oil contents have been reported in the range of $0.69 \%$ to $14.70 \%$ the higher content being in fennel seeds (Badoc et al., 1994; Dnyansagar and Jahagirdar, 1980; Garcia-Jimenezetal.,2000; Marotti etal., 1994).

Similar to the observations, Badoc et al. (1994), Dnyansagar and Jahagirdar (1980) and Marotti et al. (1994) reported that cultivar can have a significant effect on essential oil content.

The results show that essential oil yields from dried herbage in Nova Scotia during 2001 and 2002 ranged from 0.05 to 1.96 $\mathrm{L} \cdot \mathrm{ha}^{-1}$. 'Sweet Fennel' produced less oil than the other two cutlivars and overall, 'Shumen' yielded better in the two sites.

The main component in essential oil from all treatments, as is typical for this species, was anethole, ranging in concentration from $47 \%$ to $80.2 \%$ depending on year, location, seeding date, and cultivar. Other major components in the essential oil were methyl chavicol, fenchone,

Table 3. Essential oil composition of fennel grown in Canning, Nova Scotia, in 2001, depending on cultivar (C) and seeding date (D).

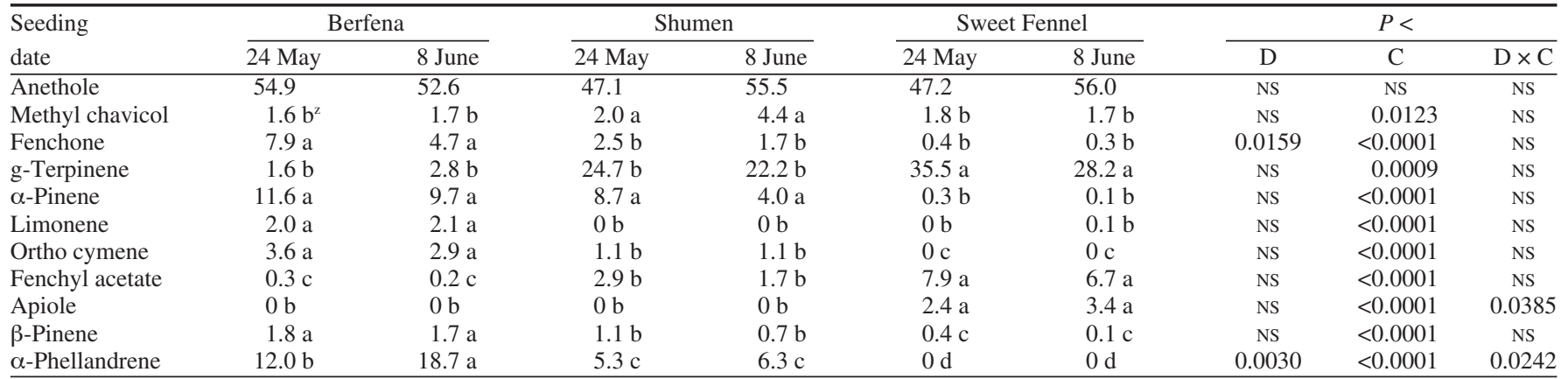

${ }^{2}$ Means within rows followed by different letters are significantly different at $P<0.05$.

Table 4. Essential oil composition of fennel grown in Truro, Nova Scotia, in 2001, depending on cultivar (C) and seeding date (D).

\begin{tabular}{|c|c|c|c|c|c|c|c|c|c|}
\hline \multirow{2}{*}{$\begin{array}{l}\text { Seeding } \\
\text { date }\end{array}$} & \multicolumn{2}{|c|}{ Berfena } & \multicolumn{2}{|c|}{ Shumen } & \multicolumn{2}{|c|}{ Sweet Fennel } & \multicolumn{3}{|c|}{$P<$} \\
\hline & 24 May & 8 June & 24 May & 8 June & 24 May & 8 June & $\mathrm{D}$ & $\mathrm{C}$ & $\mathrm{D} \times \mathrm{C}$ \\
\hline Methyl chavicol & $0.2 \mathrm{~b}$ & $2.1 \mathrm{~b}$ & $3.7 \mathrm{a}$ & $2.7 \mathrm{a}$ & $2.3 \mathrm{~b}$ & $2.0 \mathrm{~b}$ & NS & 0.0025 & NS \\
\hline Limonene & $1.3 \mathrm{~b}$ & $1.9 \mathrm{a}$ & $0 \mathrm{~b}$ & $0.4 \mathrm{~b}$ & $3.5 \mathrm{a}$ & $3.7 \mathrm{~b}$ & NS & 0.0484 & NS \\
\hline$\alpha$-Pinene & $1.0 \mathrm{a}$ & $0.9 \mathrm{a}$ & $0.3 \mathrm{~b}$ & $0.6 \mathrm{~b}$ & $0 \mathrm{c}$ & $0 \mathrm{c}$ & NS & $<0.0001$ & NS \\
\hline Ortho cymene & $4.0 \mathrm{a}$ & $5.0 \mathrm{a}$ & $2.0 \mathrm{~b}$ & $2.5 \mathrm{~b}$ & $0 \mathrm{c}$ & $0 \mathrm{c}$ & NS & $<0.0001$ & NS \\
\hline$\alpha$-Phellandrene & $5.8 \mathrm{~b}$ & $12.5 \mathrm{a}$ & $1.7 \mathrm{~cd}$ & $4.0 \mathrm{bc}$ & $0 \mathrm{~d}$ & $0 \mathrm{~d}$ & 0.0056 & $<0.0001$ & 0.0024 \\
\hline
\end{tabular}

${ }^{2}$ Means within rows followed by different letters are significantly different at $P<0.05$.

Table 5. Essential oil composition of fennel grown in Canning, Nova Scotia, in 2002, depending on cultivar (C) and seeding date (D).

\begin{tabular}{|c|c|c|c|c|c|c|c|c|c|}
\hline \multirow{2}{*}{$\begin{array}{l}\text { Seeding } \\
\text { date }\end{array}$} & \multicolumn{2}{|c|}{ Berfena } & \multicolumn{2}{|c|}{ Shumen } & \multicolumn{2}{|c|}{ Sweet Fennel } & \multicolumn{3}{|c|}{$P<$} \\
\hline & 24 May & 8 June & 24 May & 8 June & 24 May & 8 June & $\mathrm{D}$ & $\mathrm{C}$ & $\mathrm{D} \times \mathrm{C}$ \\
\hline Methyl chavicol & $2.0 \mathrm{~b}^{2}$ & $2.2 \mathrm{~b}$ & $3.1 \mathrm{a}$ & $2.7 \mathrm{a}$ & $2.1 \mathrm{~b}$ & $2.1 \mathrm{~b}$ & NS & 0.0002 & NS \\
\hline g-Terpinene & $2.0 \mathrm{~b}$ & $1.1 \mathrm{~b}$ & $18.3 \mathrm{a}$ & $16.6 \mathrm{a}$ & $25.5 \mathrm{a}$ & $15.1 \mathrm{a}$ & NS & $<0.0001$ & NS \\
\hline$\alpha$-Pinene & $11.7 \mathrm{a}$ & $3.6 \mathrm{~b}$ & $4.8 \mathrm{~b}$ & $3.2 \mathrm{~b}$ & $0.3 \mathrm{bc}$ & $0.1 \mathrm{c}$ & $<0.0001$ & $<0.0001$ & 0.0001 \\
\hline Limonene & 1.7 & 1.0 & 0 & 0 & 0 & 2.4 & NS & NS & NS \\
\hline Ortho cymene & $1.6 \mathrm{a}$ & $1.0 \mathrm{a}$ & $0.5 \mathrm{~b}$ & $0.4 \mathrm{~b}$ & $0 \mathrm{c}$ & $0 \mathrm{c}$ & NS & $<0.0001$ & NS \\
\hline Apiole & $0 \mathrm{~b}$ & $0.1 \mathrm{~b}$ & $0 \mathrm{~b}$ & $0 \mathrm{~b}$ & $1.1 \mathrm{a}$ & $1.4 \mathrm{a}$ & NS & 0.0008 & NS \\
\hline$\beta$-Pinene & $1.5 \mathrm{a}$ & $1.0 \mathrm{a}$ & $0.8 \mathrm{~b}$ & $0.7 \mathrm{~b}$ & $0.8 \mathrm{~b}$ & $0.4 \mathrm{~b}$ & 0.0003 & $<0.0001$ & NS \\
\hline$\alpha$-Phellandrene & $14.9 \mathrm{a}$ & $15.7 \mathrm{a}$ & $7.8 \mathrm{~b}$ & $6.9 \mathrm{~b}$ & $0.0 \mathrm{c}$ & $0 \mathrm{c}$ & NS & $<0.0001$ & NS \\
\hline
\end{tabular}

${ }^{2}$ Means within rows followed by different letters are significantly different at $P<0.05$.

Table 6. Essential oil composition of fennel grown in Truro, Nova Scotia, in 2002, depending on cultivar (C) and seeding date (D).

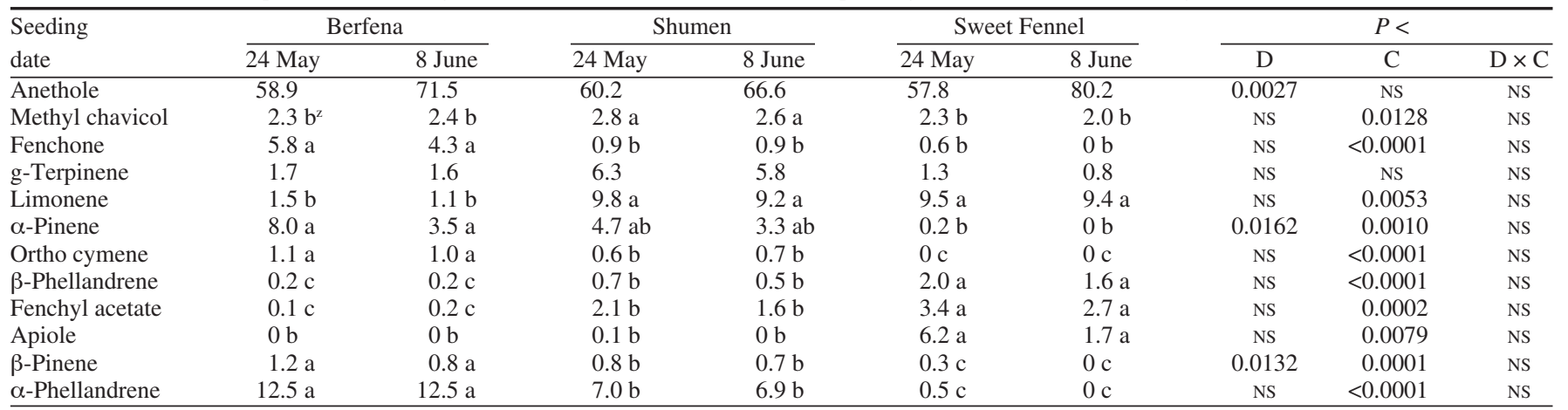

${ }^{2}$ Means within rows followed by different letters are significantly different at $P<0.05$. 
Table 7. Essential oil composition of 'Sweet Fennel' grown in the U.S.

\begin{tabular}{|c|c|}
\hline Component & Conen \\
\hline Anethole & 77.06 \\
\hline Fenchone & 9.83 \\
\hline Methyl chavicol & 4.46 \\
\hline Limonene & 3.34 \\
\hline$\alpha$-Pinene & 2.27 \\
\hline$\underline{P e r c e n t ~ i d e n t i f i e d ~}$ & 96.96 \\
\hline
\end{tabular}

g-terpinene and $\alpha$-pinene. Minor components of the oil were ortho cymene, $\beta$-phellandrene, fenchyl acetate, $\beta$-pinene, $\alpha$-phellandrene, and apiole.

Essential oil composition was unique to each cultivar. Essential oil from 'Shumen' was highest in methyl chavicol. g-Terpine, fenchyl acetate and apiole were detected at the highest levels in 'Sweet Fennel' oil, but fenchone, compounds $\beta$-pinene, $\alpha$-phellandrene, ortho cymene and $\alpha$-pinene were in lower concentrations in 'Sweet Fennel' oil than the other cultivars. Fenchone, ortho cymene, $\beta$-pinene, $\alpha$-phellandrene, and $\alpha$-pinene were greatest in 'Berfena' oil while fenchyl acetate was lowest in this cultivar's oil.

In both years and locations various components were affected by the delay in seeding. In 2002, anethole was lower in the first seeding date, however in 2001 (Truro) anethole was decreased by the delay in seeding. g-Terpinene was decreased by the delay in seeding, but ortho cymene, $\beta$-pinene, $\beta$-phellandrene, $\alpha$-pinene, and fenchone were greater in the first seeding date.

In a study by Peterson et al. (1993) of 'C25', an improved seedline from Pernod Richard, fennel grown in southern Tasmania, anethole (65\% to $70 \%$ ), fenchone (15\% to $17 \%$ ), methyl chavicol $(2 \%$ to $3 \%)$, $\alpha$-phellandrene $(8 \%$ to $10 \%)$, and limonene (2\%) were the main components of fennel oil. Simandi et al. (1999) reported trans-anethole, fenchone, methyl chavicol, and limonene as the main components of fennel purchased at a local market in Hungary. Similarly anethole, fenchone, limonene, and methyl chavicol were main components of 'Sweet Fennel' grown in Ancona province, Italy (Marotti et al., 1994). Minor components of essential oil of fennel grown in the central region of Portugal were reported to be $\alpha$-pinene, camphene, $\beta$-pinene, myrcene, $\alpha$-phellandrene, limonene, 1,8-cineole, $\gamma$-terpinene, p-cymene, and $\alpha$-fenchol (Cavalerio et al., 1993). The reported compositions were similar to those obtained in this study.

Anethole, limonene, and fenchone have been reported to be greatly influenced by both cultivar and harvest stage (Marotti et al., 1994). This was similar to the results reported here where seeding date and cultivar influenced the same components. From fennel collected in Spain there was great variation in essential oil composition with one chemotype being high in anethole and the second only having trace amounts (0.9\%) (Garcia-Jimenez et al., 2000), highlighting how variable the oil composition can be.

'Sweet Fennel' has been classified as having low fenchone content, usually not $>5 \%$ and anethole content could reach $84 \%$ to $90 \%$. In contrast, bitter fennel has a lower anethole concentration, $61 \%$ to $70 \%$ (Simandi et al., 1999). The fennel grown in Nova Scotia 'Sweet Fennel' and 'Shumen' contained below 5\% fenchone, but 'Berfena' contained up to $7.9 \%$ fenchone. Oil extracted from 'Sweet Fennel' contained the lowest amount of fenchone with only trace amounts detected. The essential oil from fennel grown in Nova Scotia further meet the requirements stated by Bilia et al. (2002) that there should not be $>10 \%$ methyl chavicol or $7.5 \%$ fenchone in the fennel essential oil.

Similar to the oil content reported here, anethole was the main component in the commercial oil extracted from the fennel seeds grown in the U.S. As the commercial oil was extracted from seeds and the essential oils from Nova Scotia were from herbage, the differences in anethole levels could be attributed to the plant maturity stage at harvest. The anethole content also varies based on botanical part. Venskutonis et al. (1996) reported $50.1 \%$ anethole in fruit and $73.6 \%$ in stems of fennel grown in Lithuania. Marotti et al. (1994) reported that as the fennel seeds matured the content of anethole increased and the limonene content decreased.

Although somewhat low the anethole content of the fennel from Nova Scotia shows promise with the essential oil from the earlier seeding date containing greater anethole concentration. Fenchone (9.83\%), methyl chavicol $(4.46 \%)$, limonene $(3.34 \%)$, and $\alpha$-pinene $(2.27 \%)$ were the remaining main components. Those components comprised of $96.96 \%$ of the essential oil with the remaining $3 \%$ of the oil being made up of numerous components in trace amounts $(<1 \%)$.

\section{Conclusions}

There is good potential for 'Berfena', 'Shumen', and 'Sweet Fennel' to be grown as an essential oil crop in the Maritime region of Canada. There was typical herbage productivity and oil composition and with earlier seeding dates, fennel in the region could mature to seeds, which would have greater oil yields. The greatest yields and tallest plants were produced by 'Shumen' and the earlier seeding date. Furthermore, the essential oil content and yields were lowest in 'Sweet Fennel' and the greatest essential oil yields were produced by 'Shumen'.

The main component in essential oil was anethole ( $47 \%$ to $80.2 \%$ ). Other major components in the essential oil were methyl chavicol, fenchone, $\alpha$-phellandrene, g-terpine, and $\alpha$-pinene. Minor components of the oil were ortho cymene, $\beta$-phellandrene, fenchyl acetate $\beta$-pinene, and apiole. The composition of each cultivar of fennel produced was unique. The composition of the oil was similar to the commercially purchased oil and met industry requirements of oil composition.

Further productivity and increased oil quality may be improved with earlier seeding to permit seed maturation. The high anethole concentration in the first seeding date of 'Shumen' and 'Sweet Fennel' essential oil is an indicator of the potential for high fennel essential oil quality from Nova Scotia. As shown there is potential to grow fennel as an essential oil crop in this region.

\section{Literature Cited}

Badoc, A., G. Deffieux, A. Lamarti, G. Bourgeois, and J.-P. Carde. 1994. Essential oil of Foeniculum vulgare Mill. (fennel) subsp. piperitum (Ueria) Cout. fruit. J. Essential Oil Res. 6:333-336.

Bilia, A.R., G. Flamini, V. Taglioli,I. Morelli, andF.F. Vincieri. 2002. GC-MS analysis of essential oil of some commercial fennel teas. Food Chem. 76:307-310.

Butain, M. and B. Chung. 1994. Effects of irrigation and nitrogen of the yield components of fennel (Foeniculum vulgare Mill.). Austral. J. Expt. Agr. 34:845-849.

Cavalerio, C.M.F., O.L. Rogue, and A.P. Da Cunha. 1993. Contribution for the characterization of Portuguese fennel chemotypes. J. Essential Oil Res. 5:223-225.

Charles, D.J. M.R. Morales, and J.E. Simon. 1993. Essential oil content and chemical composition of finocchio fennel. p. 570-573. In: J. Janick and J.E. Simon (eds.). New crops. Wiley, New York.

Clark, R.J. and R.C. Menary. 1979 Effects of photoperiod on the yield and composition of peppermint oil. J. Amer. Soc. Hort. Sci. 104:699-702.

Dnyansagar, V.R. andH.A. Jahagirdar. 1980. Induced mutants of Foeniculum vulgare in relation to seed and essential oil content, p. 286-291. In: S. S. Bir (ed.). Recent researches in plant sciences. Kalyani Publ., New Delhi, India.

Embong M.B., D. Hadziyev, and S. Moinar. 1977. Essential oils from spices grown in Alberta, fennel oil (Foeniculum vulgare var. Dulce). Can. J. Plant Sci. 57:829-837.

Fahlen, A., M. Welander, and R. Wennersten. 1997. Effects of light-temperature regimes on plant growth and essential oil yield of selected aromatic plants. J. Sci. Food Agr. 73:111-119.

Frank, J.R., J.J. Baron, and R.T. Guest. 1987. Pesticides for use in herbs, spices and medicinal plants. Herb Spice Medicinal Plant Dig. 5:1-12.

Garcia-Jimenez, N., M.J. Perez-Alonso, and A. VelascoNegueruela. 2000. Chemical composition of fennel oil, Foeniculum vulgare Miller, from Spain. J. Essential Oil Res. 12:159-162.

Gill, B.S. and G.S. Randhawa. 1996. Effect of different transplanting dates and harvesting stages on the quality of French basil oil. J. Herbs Spices Medicinal Plants 4:35-42.

Gupta, K., K.K. Thakral, and S.K. Arora. 1995. Metabolic changes of biochemical constituents in developing fennel seeds (Foeniculum vulgare) J. Sci. Food Agr. 68:73-76.

Guenther, E. 1948. The essential oils, p. 427. vol. 1. Van Nostrond Co. Inc., New York.

Kothari, S.K., J.P. Singh, and K. Singh. 1989. Chemical weed control in Bulgarian coriander (Coriandrum sativum L.). Trop. Pest Mgt. 35:2-5.

Kothari, S.K. and K. Singh. 1994. Chemical weed control in japanese mint (Mentha arvensis L.). J. Essential Oil Res. 6:47-55.

Lenardis, A., E. de la Fuente, A. Gil, and A. Tubia. 2000. Response of coriander (Coriandrum sativum $\mathrm{L}$.) to nitrogen availability. J. Herbs Spices Medicinal Plants 7:47-58.

Marotti, M., R. Piccaglia, andE. Giovanelli. 1996. Differences in essential oil composition of basil (Ocimumbasilicum L.) Italian cultivars related to morphological characteristics. J. Agr. Food Chem. 44:3926-3929.

Marotti, M., R. Piccaglia, and E. Giovanelli. 1994. Effects of variety and ontogenetic stage on the essential oil composition and biological activity of fennel (Foeniculum vulgare Mill.). J. Essential Oil Res. 6:57-62.

Peterson, L.E., R.J. Clark, and R.C. Menary. 1993. Umbel initiation and stem elongation in fennel (Foeniculum vulgare) initiated by photoperiod. J. Essential Oil Res. 5:37-43.

Reichardt, I. and F. Pank. 1993. Methods and results of breeding a fennel variety (Foeniculum vulgare Mill.) for annual cultivation. Acta Hort. 330:185-190.

SAS Institute. 2000. SAS version 8. SAS Inst., Cary, N.C.

Simandi, B., A. Deak, and E. Ronyal. 1999. Supercritical carbon dioxide extraction and fractionation of fennel oil. J. Agr. Food Chem. 47:1635-1640.

Venskutonis, P.R., A. Dapkevicius, and T.A. van Beek. 1996. Essential oils of fennel (Foeniculum vulgare Mill.) from Lithuania. J. Essential Oil Res. 8:211-213.

Zheljazkov, V. and I. Zhalnov. 1995. Effect of herbicides on yield and quality of Coriandrum sativum L. J. Essential Oil Res. 7: 633-639.

Zheljazkov V.D., Y. Yankuloff, R. Raev, S. Stanev, A. Margina, and N. Kovatcheva. 1996. Achievements in breeding on medicinal and aromatic plants in Bulgaria, p. 142-145. In: F. Pank (ed.). Breeding research in aromatic and medicinal plants. Jahrgang, Heft 1, 1996. 